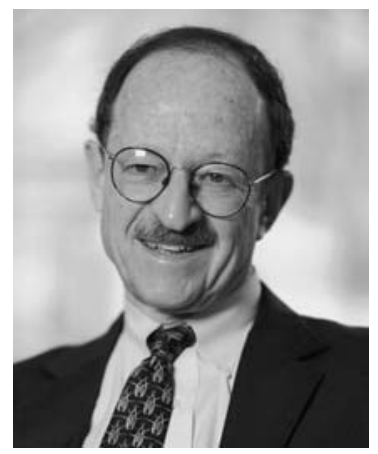

\title{
A Conversation with Harold Varmus
}

\author{
INTERVIEWER: JAN WITKOWSKI \\ Executive Director, Banbury Center at Cold Spring Harbor Laboratory
}

Harold Varmus is the Lewis Thomas University Professor of Medicine at Weill Cornell Medicine and a Senior Associate at the New York Genome Center.

Jan Witkowski: I thought we might start by reflecting on the history of this field. The first Cold Spring Harbor symposium for which the words "cancer" or "tumor" appeared in the title was the Tumor Virus Meeting in 1974. That was largely to do with the biology of the viruses rather than the cancer-causing ability.

Dr. Varmus: Yes, I think that's right in one sense: we knew more about the replication strategies of those viruses than about how they caused tumors. But many, even most, of the people who came to that symposium were interested in cancer; they were drawn to the study of tumor viruses, either those that carried their genes as DNA, like SV40 virus, or as RNA, like Rous sarcoma virus and other retroviruses, because those viruses were able to change a normal cell into a cancer cell and cause frank cancers, solid tumors or leukemias, in animals. For those of us who believed that cancer probably had its origins in genetics, these viruses, which have very few genes but are capable of changing a complex mammalian or avian cell into a cancer cell, offered promise for understanding some fundamental aspects of carcinogenesis at a time before we had molecular cloning and DNA sequencing and all these things that make modern eukaryotic genetics possible. At that time, we had no idea how many genes were actually in a eukaryotic cell. We were looking for simple ways to ask what sort of genes might be able to mediate this dramatic change between normal cell behavior and the excessive growth that is characteristic of cancer cells.

Jan Witkowski: By the time of the next Cancer Symposium in '79, the title of which was "Viral Oncogenes," the field was transformed.

Dr. Varmus: It was and it wasn't. We did know a lot more about viral cancer genes by then, but we also knew something about them in '74. In fact, some of the most important mutations in viral cancer genes-mutations that defined the cancer-causing functions of those genes-had been identified in the late '60s and early '70s. They included, for example, the temperature-sensitive and nonconditional deletion mutants of Rous sarcoma virus, first isolated in the late ' 60 s and early ' 70 s. One of the reasons that viral oncogenes became so much more important in the late ' $70 \mathrm{~s}$ is because we knew, in the case of the retroviruses, that every one of those retroviral cancer genes was derived from a normal cellular gene, and we had much greater capacity to study those genesto figure out what kind of proteins they made, how they became cancer-causing, and how they affected cell functions, like growth - when they were incorporated into viral genomes. At that point, recombinant DNA technology was available, but it had not yet been widely applied to the study of cancer genes from eukaryotic cells because of restrictions on the use of the technology.

Jan Witkowski: Was it a surprise that cells had genes in them that, when mutated, could make them cancerous?

Dr. Varmus: At the symposium in ' 79 , that was still a prediction based on comparisons between viral oncogenes and their cellular progenitors, called proto-oncogenes. Strong evidence that at least some of those genes contributed to human cancers by undergoing mutationsfor instance, point mutations or chromosomal translocations - came a few years later. Those discoveries were both surprising and gratifying. Many theories existed about how cancer might arise, some dating back to the early days of the 20th century. One of those ideas, first outlined by the developmental biologist Theodor Boveri, was that normal cellular genes could drive a cell to behave abnormally if they became too numerous or were deleted. What I think everybody was very surprised by was the idea that some of the human genes with that potential could be found by using the genes that were present in tumor viruses of chickens or mice or cats. That was the big surprise.

When I entered the tumor virus field in 1970, we already knew that there was at least one gene in a virus like the Rous sarcoma virus that was required to elicit cancer-

(C) 2016 Varmus. This article is distributed under the terms of the Creative Commons Attribution License, which permits unrestricted reuse and redistribution provided that the original author and source are credited. 
ous behavior in an avian or mammalian cell after infection. Our group-Mike Bishop and I-approached this problem initially without a preconceived idea of where it might lead, thinking, "We're going to be studying a virus that has only a few genes and at least one of those genes we know to be involved in viral carcinogenesis." The idea that the gene would itself be a slightly altered version of a normal cellular gene was certainly not what I expected. I thought it might be similar to a gene that is present in a normal cell. In retrospect, you can view subsequent developments as an early stage of the Human Genome Project: finding out what proved to be the normal versions of human cancer genes by studying the 20 or 30 retroviruses that were known to cause cancer in animals.

Jan Witkowski: That led to a whole raft of similar genes being identified.

Dr. Varmus: It turns out that the Rous sarcoma virus was, for experimental purposes, the best possible virus to work with. It was fully competent to grow (by doing all of those interesting things during the viral life cycle that we talked about at the 1974 symposium). But it also had the ability to transform cells. Many of the other so-called oncogenic or transforming retroviruses were more complicated. The highly oncogenic viruses were defective for replication. Other closely related viruses could replicate, but not transform cultured cells and induced tumors in animals only very slowly if at all. These two kinds of viruses, competent for replication or able to transform cells efficiently, had to grow together to propagate the transforming virus. Rous sarcoma virus was different, simplifying both genetic and molecular studies; it proved to be a great experimental tool and we were lucky to have started with it.

Jan Witkowski: Do you know if Jim Watson was disappointed that his bet on DNA tumor viruses didn't come out?

Dr. Varmus: DNA tumor viruses taught us a lot about DNA synthesis and gene expression in eukaryotic cells, including RNA splicing, in the 60 s and $70 \mathrm{~s}$; then, in the 80 s, they were illuminating about the functions of another set of genes important in human neoplasia, the tumorsuppressor genes. And much of that work was done at Cold Spring Harbor. The route to discovery of tumorsuppressor genes was just a little more complicated, involving chromosomal abnormalities, hereditary cancers (like retinoblastomas), and the binding of viral oncoproteins, T antigens, to cellular proteins like P53. So the role of DNA tumor viruses ended up being incredibly heuristic. Further, Jim was very excited by the discovery of cellular oncogenes and did not seem to regret having placed most of his bets on the DNA tumor viruses. They taught us a lot.

Jan Witkowski: Once people have got hold of genes, you could look at proteins, and you could then begin to look at functions of the normal proteins.

Dr. Varmus: You could. But it was surprisingly difficult to identify the product of the Rous sarcoma virus onco- gene, called src. The gene had been defined by both temperature-sensitive and deletion mutants around 1970. But it wasn't until 1975 when Joan Brugge, working with Ray Erikson, first showed the gene makes a $60-\mathrm{kDa}$ protein. It took another few years before we understood it was a protein kinase, and another couple of years before Tony Hunter and his colleagues showed that src protein was a kinase of a special kind because it adds phosphate not to the most commonly phosphorylated amino acids, serine and threonine, but to tyrosine. So it took 10 years to go from the identification of this gene as defined by temperature-sensitive mutations to the demonstration that it makes a protein tyrosine kinase that transforms cells when it is not properly regulated. Over the next several years, a community effort revealed that it was only one of what turned out to be roughly 90 tyrosine kinases, many of which are encoded by proto-oncogenes and are now the targets for some of the most effective drug therapies in human cancers driven by mutant versions of those genes.

Jan Witkowski: That led into things like the cell cycle, which was the topic of the '91 symposium.

Dr. Varmus: The proto-oncogenes discovered through the study of retroviruses were actually less central to identification of the cell cycle machinery than were the DNA tumor virus oncoproteins that interact with tumor suppressors. The DNA virus oncogenes that control the activities of the retinoblastoma, E2F, and p53 proteins played a bigger role in the cell cycle symposium than did retroviral oncogenes. The products of proto-oncogenic precursors of retroviral oncogenes have several roles in delivering growth signals from the cell surface to the transcriptional apparatus; but many of the components that govern the cell cycle itself — not all, but many of themare central to the mechanism by which DNA tumor viruses transform cells.

Jan Witkowski: Presumably, as the genes and the proteins for normal cells were examined, the role of viruses in this research diminished.

Dr. Varmus: You could argue that, because recombinant DNA technology now permits us to isolate or make DNA, RNA, or protein and manipulate the functions of cancer genes in various ways. But I think it is important to remember that tumor viruses, both RNA and DNA, remain very important in several ways. For instance, the work that was done on retroviruses that cause tumors in chickens and mice taught us many things about how retroviruses grow, more than a decade before we knew what caused AIDS. And, of course, AIDS is caused by a retrovirus that is very similar in its growth strategy to other retroviruses, so we were serendipitously well prepared for the discovery of HIV. Retroviruses also remain essential laboratory and clinical instruments - vectors - for introducing genes into cultured cells and patients. I think people have to understand that the investment that was made in tumor viruses because they cause cancer taught us about a class of viruses that ended up being important in many other ways too. 
Jan Witkowski: Tell us a bit about what you are doing now.

Dr. Varmus: For the last 20 or 25 years - ever since I became less of a tumor virologist and more of a cancer biologist - my lab has been looking at mechanisms by which normal cells become cancer cells. In a sense, it's still the same general question but it's being looked at in a different way. Our world has been transformed by highthroughput sequencing and the development of highly detailed genetic maps of cancer cells compared to normal cells in patients in which those cancers have arisen. Our community now knows a lot about the complex pattern of genetic mutations and about the physiological changes that are involved in turning a normal cell into a cancer cell. From that rich repertoire of mutations and other kinds of changes, new therapies have evolved. There's discovery of cancer genes; there's novel therapeutics. In between, there's a rich terrain in which many of us are trying to understand how the constellations of mutations, different in every single tumor, end up causing a cell to be cancerous and yet have certain vulnerabilities.

More specifically, we're studying three things about this general situation.

One is how mutations that affect splicing factors and perturb normal RNA splicing patterns help to make cells cancerous.

The second is an effort to understand why certain kinds of mutations are found in certain kinds of cancer. What is it about the cell type in which those mutations are found that make the mutations more "penetrant" in those cells? In other words, why do those mutations give rise to what we call the cancer phenotype in that cell type? What accounts for the behavior and appearance of cells in small cell lung cancer, squamous cell lung cancer, and adenocarcinoma of the lung, three very distinct pathological types of cancer that have rather distinct patterns of mutation, although they all arise in the lung from cells belonging to one developmental lineage?

The third, the one I discussed at this year's symposium, is why certain mutations that are commonly seen-for example, in lung adenocarcinomas - don't occur together. It's been very striking to those who have sequenced literally hundreds of tumors of a certain type that certain genes can be found mutated in perhaps $10 \%, 20 \%$, or $30 \%$ of the tumors, and yet never be found mutated in the same tumor. Why is that? Is it because there's no selective pressure for the second mutations once the first has occurredfor example, because they exert identical physiological effects - or is it because the two together are synthetically damaging? As far as we can tell from the common examples we have studied, the latter is the case. That's interesting because one of the things we're trying to do is to figure out some novel ways to approach therapeutics.

Traditionally, people say, "your cancer is driven by a bad gene, so inhibit or eliminate the protein that bad gene makes." Another way to think about the problem is to say, "When you have a bad gene driving your cancer, it creates a kind vulnerability in the cells such that the cells can't tolerate the loss of some other gene." It is possible there's another kind of vulnerability, a vulnerability to hyperactivity of some other genes. What we're looking for in this situation is a lethal conspiracy that occurs when both an oncogene commonly affected in many types of cancer, the so-called KRAS gene, is combined with a mutant epidermal growth factor receptor (EGFR) gene. If we can understand why those two are not tolerated by cells, and we can mimic that in a patient with cancer, we could have a new approach to therapy.

Jan Witkowski: It sounds as though you've got a cancer cell with a ras mutation that's the driver of that cancer. You're now going to introduce another bad gene into that stage?

Dr. Varmus: We call them bad, but we only call them bad because the cancers kill the patient. A ras mutant is not bad for the cell. It gives the cell a selective advantage. It grows more, it dies less, it drives the cell to success. Success for the cell is becoming a tumor. It's not good for the patient, but it's good for the cell. Surprisingly, if you have two of these bad actors in the same cell, they conspire to make life difficult for the cell. That's potentially a good thing for the patient. What we're trying to do is exploit the toxicity of having two cancer-causing genes in the same cell. Obviously there are probably many occasions in which there are multiple cancer-causing genes in the same cell, but they don't have a toxic effect on the cell. Some combinations do, and one way to identify those is to look through these reams of data for mutations that are common but are mutually exclusive - they do not occur together. If we understand why a combination is bad for the cell, we might be able to mimic that situation with a drug that has little or no effect on normal cells while specifically damaging the cancer cells.

Jan Witkowski: How many such pairs have you found?

Dr. Varmus: We've looked at a few just by using computational methods to look at patterns of mutations. We haven't subjected them all to biological tests ourselves, although other labs have looked at a few of these combinations and have seen some form of cellular damage or growth arrest in those cases. I don't believe that every mutually exclusive pair is going to prove to be damaging, but some will. Other laboratories will need to join us in this endeavor and try to enumerate which of the combinations are synthetically toxic. There's potential for doing something important here if we could understand how that damage is mediated. Is there some switch, some change in behavior of the cell that we can understand and manipulate?

Jan Witkowski: Presumably, you needn't introduce a second mutation if you understand the consequence of that second mutation. There could be something downstream that you can manipulate.

Dr. Varmus: Yes, very likely. But we also need to remember that cells are capable of adapting to escape damage, and those that do learn to escape become the dominant component through an evolutionary process. 
For instance, one of the things we're learning as we treat cancers with drugs that inhibit a single oncogenic protein is that cancer cells have a lot of ways to escape the effect of a drug. Drug resistance can most simply occur because of a secondary mutation affecting the target site for the drug, but it can also occur because the cell undergoes a rewiring to work in a different way. Many people are now looking for ways to put one kind of therapy together with another so that cells have a harder time finding a way around the therapeutic inhibitor. The same logic may apply to efforts to induce synthetic lethality. Still, there is great potential here for understanding a cell's wiring system better; for example, there are both negative and positive forces that operate in these signaling networks. Grasping the logic of such signaling systems is likely to yield new ways to think about therapeutics.

Jan Witkowski: Let's spend a couple minutes on a bit of sociology: preprints. You've long been an advocate of open access publishing and data sharing. Are preprint servers a further development of that?

Dr. Varmus: They're a further development in the sense that they represent another change in publication practices in biology. There are two points I would make. First, providing your work as a preprint by putting it online before it's been reviewed by peers is very different from open access publication with peer review. Both methods make work accessible to all at no cost to the reader, but preprint servers are simply inexpensive mechanisms for getting work very quickly to readers. Open access journals, with their review processes have significant costs that have to be met, for example, by charging a fee to the authors. Secondly, the public posting of preprints is not really new. It is only new to biology. In physics, mathematics, astrophysics, and computational sciences, people were doing this through a preprint server called "arXiv" ever since Paul Ginsparg developed it in 1991. So it's been around a long time, and most of the well-known journals that we all use, like Nature and Sci- ence, are perfectly comfortable accepting a paper that was posted as a preprint a year or 2 or 3 years earlier for formal publication after traditional peer review. Preprints therefore don't really break new ground as a publishing practice, but they break new ground in biology. We're all hemmed in by our cultural traditions.

Jan Witkowski: Why do you think biologists are uncomfortable with preprints?

Dr. Varmus: I'm not entirely sure whether it's inherent to the nature of the life sciences. Some people argue that it is, because of the size of our field and the patentability of some of our work. But I don't think so. I think what happened is that we simply didn't adopt it when the physicists did. Perhaps some leaders didn't see a big need for it and didn't adopt it, even though some of them began their careers in physics or math. I'm not sure why we didn't see a need for it when physicists took it up so avidly; maybe because we had a lot of meetings at Cold Spring Harbor and elsewhere to talk about our results.

But now there are other factors. Everyone is worried about the competition for jobs and grants. So much of what determines who's going to advance in their career now depends on publication in certain traditional journals, especially the most highly ranked journals; so people are very nervous about changing their publication practices.

This is a cultural element that we need to fight. For one thing, we should not be evaluating each other based on what journal we publish in; we should be evaluating each other based on the quality of our work. Secondly, we have to remember that as scientists we are paid to spend these highly enjoyable years of our lives working with brilliant colleagues to make discoveries and share them with our colleagues. What better way to do that than to get our work out early in a preprint that you can still publish in a distinguished journal later on. The journals, excepting one or two, are not resistant to this. And we, our colleagues, and the public can all benefit from faster communication, with minimal if any risk or expense. 


\section{$\$_{\text {CSH\& }}^{\infty}$ Cold Spring Harbor Symposia SYMPOSIA}

\section{A Conversation with Harold Varmus}

Cold Spring Harb Symp Quant Biol 2016 81: 347-350 originally published online February 16, 2017

Access the most recent version at doi:10.1101/sqb.2016.81.031641
Creative This article is distributed under the terms of the
Commons http://creativecommons.org/licenses/by/4.0/, which permits unrestricted
License reuse and redistribution provided that the original author and source are credited.

Email Alerting Receive free email alerts when new articles cite this article - sign up in Service the box at the top right corner of the article or click here. 